Article

\title{
A New Method for Continuous Monitoring of Black and Odorous Water Body Using Evaluation Parameters: A Case Study in Baoding
}

\author{
Xueying Zhou ${ }^{1}{ }^{D}$, Zhaoqiang Huang ${ }^{2, *(\mathbb{D})}$, Youchuan Wan ${ }^{1}$, Bin $\mathrm{Ni}^{2}$, Yalong Zhang ${ }^{2}$, Siwei Li ${ }^{1}, \mathrm{Mingwei} \mathrm{Wang}^{3}$ \\ and Tong $\mathrm{Wu}^{4}$ \\ 1 School of Remote Sensing and Information Engineering, Wuhan University, Wuhan 430079, China; \\ zhouxueying_rs@whu.edu.cn (X.Z.); ychwan@whu.edu.cn (Y.W.); siwei.li@whu.edu.cn (S.L.) \\ 2 Institute of Mineral Resources, China Metallurgical Geology Bureau, Beijing 101300, China; \\ nibin@cmgb.cn (B.N.); zhangyalong@cmgb.cn (Y.Z.) \\ 3 School of Computer Science, Hubei University of Technology, Wuhan 430068, China; wmwscola@hbut.edu.cn \\ 4 State Key Laboratory of Remote Sensing Science, College of Global Change and Earth System Science, \\ Beijing Normal University, Beijing 100875, China; 201831490019@mail.bnu.edu.cn \\ * Correspondence: huangzhaoqiang@cmgb.cn
}

check for

updates

Citation: Zhou, X.; Huang, Z.; Wan, Y.; Ni, B.; Zhang, Y.; Li, S.; Wang, M.; $\mathrm{Wu}, \mathrm{T}$. A New Method for Continuous Monitoring of Black and Odorous Water Body Using Evaluation Parameters: A Case Study in Baoding. Remote Sens. 2022, 14, 374. https://doi.org/10.3390/rs14020374

Academic Editors: Lifu Zhang, Yuanzhi Zhang, Yi Guo, Kun Shi, Qian Shen and Teodosio Lacava

Received: 19 November 2021

Accepted: 8 January 2022

Published: 14 January 2022

Publisher's Note: MDPI stays neutral with regard to jurisdictional claims in published maps and institutional affiliations.

Copyright: (C) 2022 by the authors. Licensee MDPI, Basel, Switzerland. This article is an open access article distributed under the terms and conditions of the Creative Commons Attribution (CC BY) license (https:// creativecommons.org/licenses/by/ $4.0 /)$.

\begin{abstract}
Water is an important factor in human survival and development. With the acceleration of urbanization, the problem of black and odorous water bodies has become increasingly prominent. It not only affects the living environment of residents in the city, but also threatens their diet and water quality. Therefore, the accurate monitoring and management of urban black and odorous water bodies is particularly important. At present, when researching water quality issues, the methods of fixed-point sampling and laboratory analysis are relatively mature, but the time and labor costs are relatively high. However, empirical models using spectral characteristics and different water quality parameters often lack universal applicability. In addition, a large number of studies on black and odorous water bodies are qualitative studies of water body types, and there are few spatially continuous quantitative analyses. Quantitative research on black and odorous waters is needed to identify the risk of health and environmental problems, as well as providing more accurate guidance on mitigation and treatment methods. In order to achieve this, a universal continuous black and odorous water index (CBOWI) is proposed that can classify waters based on evaluated parameters as well as quantitatively determine the degree of pollution and trends. The model of CBOWI is obtained by partial least squares machine learning through the parameters of the national black and odorous water classification standard. The fitting accuracy and monitoring accuracy of the model are 0.971 and 0.738 , respectively. This method provides a new means to monitor black and odorous waters that can also help to improve decision-making and management.
\end{abstract}

Keywords: black and odorous water; continuous monitoring; water quality; evaluation index; Xiong'an New Area; Baoding

\section{Introduction}

One of the most intractable problems in water quality is black and odorous waters. These are water bodies characterized as having an unpleasant color and odor that can be caused by a variety of different biogeochemical reactions [1]. It is mainly due to a series of physical (e.g., temperature) [2], chemical (e.g., FeS and/or MnS in overlaying water formed by the combination of $\mathrm{Fe}^{2+}$ or $\mathrm{Mn}^{2+}$ with $\mathrm{S}^{2-}$ ) [3] and biological (e.g., algae) [4] reactions of pollutants in the water under hypoxic or anaerobic conditions [5]. As it affects socio-economic development, it is important that efficient, accurate techniques suited to evaluating black and odorous water bodies be developed.

The phenomenon of black and odorous water bodies in China has existed for decades [1]. Due to the cities' continuous expansion and development, $17.2 \%$ of rivers or $24.7 \%$ of lakes 
have been polluted [6,7]. According to the results jointly issued by the Ministry of Housing and Urban-Rural Development and the Ministry of Environmental Protection, more than $70 \%$ of China's cities have a black and odorous water body, of which approximately 1595 are rivers and 256 are lakes [1,8]. To address this, the Chinese government has also promulgated and adopted some policies against this [9]. As an important urban problem, black and odorous water bodies not only have a significant impact on the living environment of residents in the city, but also pose huge potential harm to health. The Action Plan for Water Pollution Prevention and Control (Water Ten Articles) issued by the State Council clearly requires that, by 2030, the black and odorous water body in urban built-up areas need to be eliminated [10].

Currently, black and odorous water bodies can be monitored mainly from two aspects. First, based on the physical and chemical properties of the black and odorous water body, traditional water quality monitoring methods, such as field sampling and laboratory analysis, are still the dominant methods [11]. These methods are of high accuracy, but they can only provide data on surface water quality at particular points in time and space [12]. Point-sampling programs can miss the overall temporal and spatial changes in the ecological environment of the entire water body, lack the ability of macro-monitoring to cover a large area and are time-consuming, labor-intensive and costly [12].

Secondly, with the advancement and development of science and technology, remote sensing plays a vital role in environmental monitoring. It can be applied to the monitoring of water quality, vegetation, drought, air pollution monitoring, etc. [13-17]. Based on the spectral difference between a black and odorous water body and a clean water body, it is possible to use remote sensing to monitor black and odorous water. This technology can overcome some of the limitations of traditional ground monitoring methods, and achieve low costs and dynamic, rapid and large-scale monitoring; thus, it is playing an increasingly important role in water monitoring [18]. Although some methods can indirectly obtain black and odor information using remote sensing technology [19], the research specifically for black and odorous water bodies is still not mature enough, and related models are in the exploratory stage $[17,20]$. Most research on it mainly focuses on the formation mechanism of different black and odorous water bodies and their evaluation methods [1,21-23], and there are few articles on the identification and monitoring of black and odorous water bodies in remote sensing images [24]. At present, the methods that use remote sensing technology can mainly be divided into two categories: the colorimetric method and index method. The colorimetric method uses density segmentation after remote sensing image transformation to identify black and odorous water bodies by image classification. It is mainly realized based on the black characteristics of the water body $[20,25,26]$. The index method analyzes the spectral information about the black and odorous water body in remote sensing images and establishes a recognition index for sensitive bands or some calculations of them, so as to distinguish black and odorous water bodies [27,28]. With the development of machine learning methods, there are also some black and odorous water extraction methods that can be combined, such as multivariate nonlinear models, neural networks or machine learning, to achieve the goal of identifying black and odorous water bodies [29-31].

For the colorimetric method, it classifies the color of the water body based on "black", but the characteristics of a black and odorous water body are not only blackness, but also odor. Although some polluted water may not appear in black or dark colors, which uses some other category, this method has limitations when polluted water and clear water have overlapping spectra or similar color, or the atmospheric correction is inaccurate, causing incorrect extraction [25]. The index method can be efficiently implemented while considering the spectral characteristics, which can reflect the black and odor features. However, the factors that cause the black and odor features are different, causing complex spectral characteristics. When using the spectral curve to analyze the difference between clean water and black and odorous water, it is effective against a small area of water, but, due to the lack of mechanism foundation, there will be certain limitations. For models that 
use water quality parameters, different parameters need to be selected according to different water bodies when modeling, which is not universal. In addition, the current evaluation indexes of black and odorous water are mostly based on empirical or semi-empirical models. Scholars are committed to studying how to model and how to choose a suitable black and odorous water classification threshold based on the true value [32]. In other words, variable and uncertain thresholds are obtained to achieve qualitative results. In order to solve the above problems, a known standard of black and odor grades, mentioned in Section 2, is used to build a continuous black and odor water index (CBOWI) for quantitative results. In detail, the monitoring parameters of black and odorous water are used as inputs, and then continuous results are reversed by the black and odor grades by machine learning. Compared with traditional laboratory testing methods, this method has a higher time resolution and more complete spatial coverage. With respect to traditional remote sensing methods (which directly establish a relationship between spectral information and water quality), our method establishes a relationship with black and odor evaluation parameters and has wider applicability because it can evaluate the state and quality of the entire water body, continuously. It provides new ideas and methods for monitoring black and odorous water bodies.

\section{Study Area and Materials}

On 1 April 2017, China made a major decision to establish Hebei Xiong'an New Area to create a model for high-quality development in China. Therefore, the water environment issues in the Xiong'an New Area need to be paid attention to. As an important component of the Xiong'an New Area, Baoding City, located in Hebei Province, was chosen as the research area in this study. Baoding is located in the middle and upper reaches of the Daqing River in the Haihe River Basin, leading to a developed water system. These water resources supply approximately 10 million people [33]. The dense population and the continuous development of Xiong'an have exacerbated the burden of water bodies. At present, the Baoding government has put forward a series of plans for the problem of water pollution. Water quality has been improved since, but the treatment cycle of black and odorous water bodies caused by domestic garbage and industrial wastewater discharge and other factors is more difficult, and the task of treatment is still challenging [34]. Figure 1 shows the main area of study. In this figure, both the yellow and red dots indicate in situ samples, while red ones also indicate image samples. Due to factors such as image quality and occlusion of ground features, a screening was performed for quality control, leading to less image samples corresponding to the in situ samples. In situ hyperspectral and water quality data, indicated by the yellow dots, were used for band selection, while the reflectance of image samples and in situ water quality data, indicated by the red dots, were used for water quality parameters' retrieval. The CBOWI model building used the water quality parameters indicated by the yellow dots. The image in the black box comes from the hyperspectral data of aircraft aerial photography. In it, there are three rivers, which were used for the evaluation of the rivers' black and odorous water by CBOWI. More detailed data information is listed in Table 1.

Table 1. Multi-source data information.

\begin{tabular}{cccc}
\hline Data & Acquisition Date & Description & Number of Points \\
\hline In situ hyperspectral data & May 2018-November 2018 & Hyperspectral radiance & 89 \\
In situ water quality data & May 2018-November 2018 & Water quality parameters & 89 \\
CASI data & June 2018-August 2018 & Hyperspectral radiance & - \\
CASI image samples & May 2018-November 2018 & Hyperspectral reflectance & 46 \\
\hline
\end{tabular}




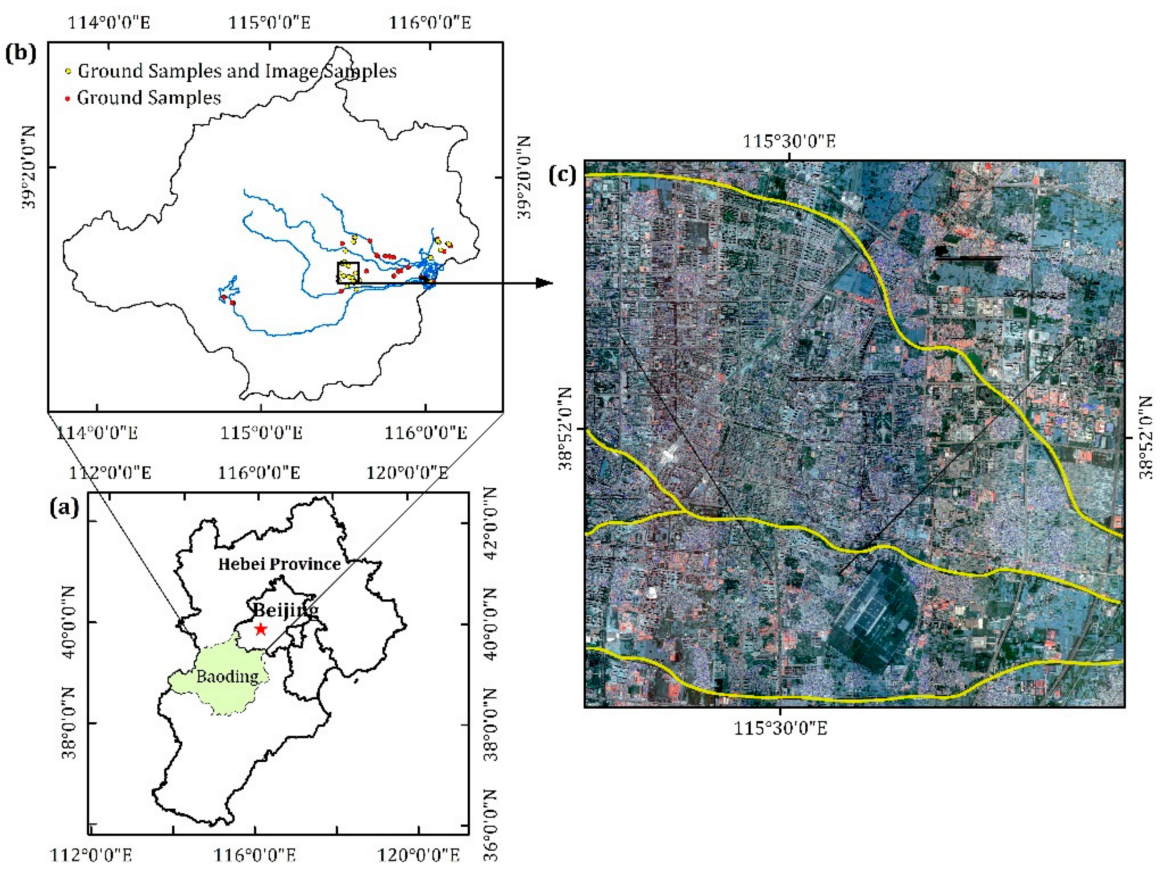

Figure 1. Study area: (a) the location of study area, (b) the location of samples, (c) river for analysis of black and odorous water.

The in situ hyperspectral water spectrum was measured by the American SVC (HR1024) spectrometer with the spectrum range of $350-2500 \mathrm{~nm}$. When measuring, we first placed the reference board flat on the ground, facing the sun. Then, we aligned the probe vertically to the reference board with a distance of approximately 10-375 px to calibrate the reference board. When measuring the target object, the probe was adjusted to the appropriate distance, aiming at the object and facing the sun. As for the in situ water quality data, they were collected using a YSI EXO2 water quality meter. The water quality data used as model parameters in this paper, measured by the instrument, included dissolved oxygen optical dissolved oxygen $(\mathrm{ODO}, \mathrm{mg} / \mathrm{L})$, oxidation-reduction potential $(\mathrm{ORP}, \mathrm{mV})$ and ammonia nitrogen $\mathrm{NH}_{3}-\mathrm{N}(\mathrm{mg} / \mathrm{L})$ as well as turbidity (TUR, FNU (FNU indicates the scattering intensity in the direction at an angle of 90 degrees with the incident light)).

Parameters mentioned above were based on the standard in the "Guide for the Remediation of Urban Black and Odorous Water Body" (hereinafter referred to as the "Guide") [35] organized and formulated by the Ministry of Housing and Urban-Rural Development, Ministry of Environmental Protection, Ministry of Water Resources, Ministry of Agriculture. Drawing on this evaluation system in the "Guide", the standard used in this paper is shown in Table 2. The parameters in this table indicate that the main characteristic of a polluted water body is a surface oxygen deficit. When determining the black and odor grade of a certain point, the maximum grade of the four parameters is used as the final black and odor water body grade. In consideration of the lack of transparency (one of the parameters in "Guide") from the instrument, TUR was used instead. The degree of obstruction that occurs when light passes through becomes turbidity. Turbidity is also an important indicator of the amount of suspended solids in the water. Studies have shown that turbidity has a good correlation with the concentration of suspended particles [36]. Generally speaking, when the turbidity reaches a certain level, the higher the turbidity, the lower the transparency. There is a certain positive correlation between the two, and the turbidity of black and odorous water body will be significantly higher than that of a non-black and odorous water body. The conversion formula of the two is as follows [37]:

$$
S D=1.489 \text { Tur }^{-0.471},
$$


where $S D$ is transparency and Tur stands for turbidity.

Table 2. Classification standards for black and odorous water body in this paper.

\begin{tabular}{ccccccc}
\hline \multicolumn{2}{c}{ Standard in "Guide" } & & & \multicolumn{3}{c}{ Standard in This Paper } \\
\hline Parameters & Mild & Severe & Parameters & Clean & Mild & Severe \\
\hline ODO $(\mathrm{mg} / \mathrm{L})$ & $0.2-2.0$ & $<0.2$ & ODO $(\mathrm{mg} / \mathrm{L})$ & $>2.0$ & $0.2-2.0$ & $<0.2$ \\
$\mathrm{ORP}(\mathrm{mV})$ & $-200-50$ & $0<-200$ & ORP $(\mathrm{mV})$ & $>50.0$ & $-200.0-50.0$ & $<-200.0$ \\
$\mathrm{NH}_{3}-\mathrm{N}(\mathrm{mg} / \mathrm{L})$ & $8.0-15$ & $>15$ & $\mathrm{NH}_{3}-\mathrm{N}(\mathrm{mg} / \mathrm{L})$ & $<8.0$ & $8.0-15.0$ & $>15.0$ \\
Transparency $(\mathrm{cm})$ & $25-10$ & $<10$ & TUR $(\mathrm{FNU})$ & $<6.2449$ & $6.2449-16.3189$ & $>16.3189$ \\
\hline
\end{tabular}

Additionally, as for the remote sensing images of the experiments, they were derived from the flight data of the aircraft. The designed relative altitude during flight was $2100 \mathrm{~m}$, the center spacing of the flight belts was $1360 \mathrm{~m}$, and the flight belt overlapped by $10 \%$. The aircraft was equipped with the CASI-1500 hyperspectral sensor introduced by the Canadian ITRES Company. The CASI data bands in the survey area were 96 bands from $957.5 \mathrm{~nm}$ to $2397.5 \mathrm{~nm}$, with the spatial resolution of $1.05 \mathrm{~m}$.

\section{Method}

This section mainly describes the method of building CBOWI: Section 3.1 describes the preprocessing method of the data used, and Section 3.2 introduces the retrieval of water quality parameters. Section 3.3 explains the modeling of CBOWI. A flow chart of the proposed method is displayed in Figure 2.

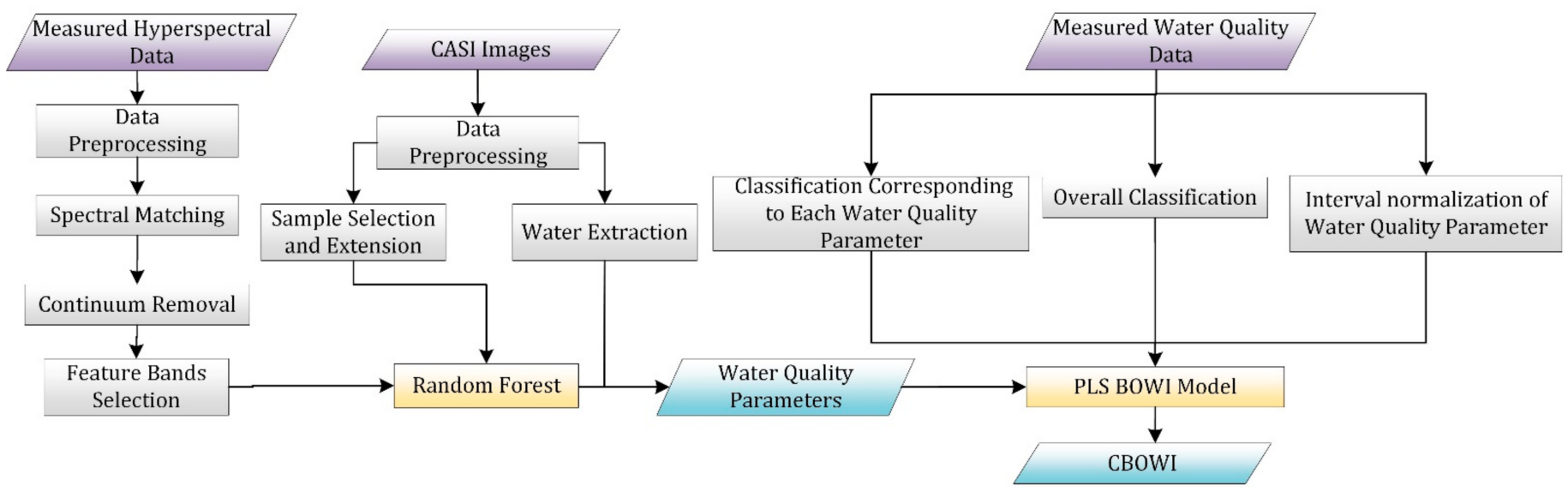

Figure 2. Overall flow chart.

\subsection{Multi-Source Data Processing}

\subsubsection{Multi-Source Data Processing}

Ground hyperspectral data need to be converted into meaningful remote sensing reflectance, which can be calculated by the following formula $[30,38]$ :

$$
R_{r s}(\lambda)=\frac{L_{w}(\lambda)}{E_{S}(\lambda)}=\frac{L_{u}(\lambda)-r L_{s k y}(\lambda)-L_{w c}(\lambda)-L_{g}(\lambda)}{\pi \times\left(L_{p}(\lambda) / \rho_{p}(\lambda)\right)},
$$

where,

$\lambda$-wavelength,

$L_{w}(\lambda)$ - the irradiance from the water,

$E_{S}(\lambda)$-the downward irradiance of the water surface,

$L_{u}(\lambda)$ - the upward radiance of the water body,

$L_{s k y}(\lambda)$ - the downward radiance of the sky light, 
$r$-a constant representing the reflectance of the water-air interface $(r=0.022)$ [38],

$L_{w c}(\lambda)$-information of white cup of sea, which is ignored here,

$L_{g}(\lambda)$-information of waves on direct sunlight, which is ignored here,

$L_{p}(\lambda)$-the radiance of the reference board,

$\rho_{p}(\lambda)$-reflectance of the reference board.

Then, a quality control procedure was conducted by analyzing the percentage of the difference between the reference spectrum data measured twice for each set of data. If the percentage of the difference was greater than a certain threshold (such as $5 \%$ ), then we discarded this set of data; otherwise, the average of the reference board measurements was taken.

After this, due to the differences in the response of each band of the spectrometer or instrument noise, the measured spectrum had burrs and other noises. Thus, the SavitzkyGolay smoothing model [39] was used to smooth the measured remote sensing reflectance. This method is used to perform polynomial regression on local data to achieve the purpose of effectively retaining the original features of the data.

Since the wavelength range, spectral interval and band number of the measured spectrum after processing were different from the CASI hyperspectral remote sensing image (Table 3), it was also necessary to align the two. This was adopted to unify the measured spectrum with the CASI sensor spectrum.

Table 3. Measured in situ and CASI spectrum information.

\begin{tabular}{cccc}
\hline & Wavelength $(\mathbf{n m})$ & Band Number & Spectral Resolution (nm) \\
\hline $\begin{array}{c}\text { In situ hyperspectral } \\
\text { data }\end{array}$ & $344.7-903.5$ & 400 & $\approx 1.5$ \\
CASI & $366.8-1047.1$ & 96 & $\approx 7.1$ \\
\hline
\end{tabular}

The CASI sensor had a fluctuation range of approximately $\pm 3.6 \mathrm{~nm}$ for the wavelength of each band. Since the final monitoring data were CASI and the measured in situ hyperspectral spectrum was more refined, in situ hyperspectral data with the smallest wavelength difference corresponding to each wavelength of CASI were selected and the others were abandoned. At the same time, in order to ensure the uniformity of the spectral range, bands 1-75 in the CASI 1-96 bands were selected, which were consistent with the measured hyperspectral range (Table 4).

Table 4. Examples of some unified bands.

\begin{tabular}{ccc}
\hline CASI (nm) & In Situ Hyperspectral Data & Difference \\
\hline 366.8 & 367.4 & 0.60 \\
374 & 373.6 & 0.40 \\
381.1 & 381.4 & 0.30 \\
388.3 & 387.7 & 0.60 \\
395.5 & 395.4 & 0.10 \\
\hline
\end{tabular}

Moreover, in order to effectively highlight the absorption and reflection characteristics of the spectrum curve, and to normalize the spectrum curve to a consistent spectrum background, we performed the envelope removal process on the measured in situ spectrum. In this way, the spectral characteristic values of different water environments could be better compared to extract characteristic bands.

\subsubsection{CASI Data}

The preprocessing technology of aerial hyperspectral data mainly includes original image radiation correction and geometric correction (using specialized software). In addition, an atmospheric correction was carried out using ENVI's FLAASH module to obtain the remote sensing reflectance calculated by the MODTRAN radiative transfer model using 
the settings of sensor, season, latitude, surface and atmosphere information. After finishing these basic steps, we used the threshold method to extract the water body, which can distinguish a water body from other ground objects based on the difference in reflectance between the water body and other ground surfaces. Figure 3 shows the typical spectral curves of ground objects based on CASI images. It can be seen from the figure that the reflectance of the water body is generally low in remote sensing images, especially in the near-infrared and mid-infrared parts [40]. Almost all incident energy is absorbed, so the reflectance of the water body is particularly low in this range [41]. The lines in green, red and gray in the figure are the reflectance curves of vegetation, artificial ground and shadows, respectively. Because vegetation and buildings absorb less energy in these bands, they have higher reflectance, while the water body has lower reflectance, which is different from other ground objects.

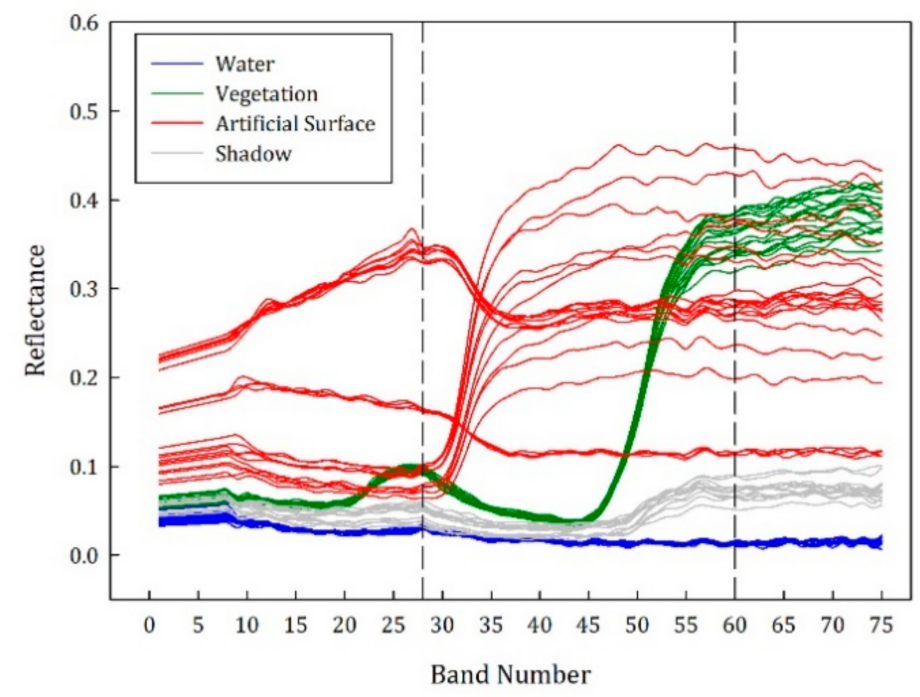

Figure 3. Spectral characteristics of typical features.

The normalized difference water index (NDWI) [42] was used to extract the water body. As shown in Figure 3, the reflection of the water body gradually weakened from the visible to the mid-infrared region, while the absorption was the strongest in the nearinfrared and the mid-infrared regions, which had almost no reflection. Therefore, the NDWI composed of the contrast between the visible light and the near-infrared band can highlight the image information about the water body, which can well suppress vegetation information. In CASI images, band 28 and band 60 represent the green and near-infrared bands, respectively for calculating NDWI. Its threshold was set as -0.3 , which is looser than usual to extract water more completely. When the NDWI is greater than -0.3 , it is judged as a water body [43].

Furthermore, the curves in the figure shows that, in some cases, the artificial ground surface is similar to the trend of water in green and near-infrared, which cannot be completely removed by NDWI alone. Additionally, shadows of some buildings or vegetation on the ground have low reflectance as well. However, regardless of the artificial ground, bare land or the shadows over vegetation, their near-infrared reflectance will be slightly higher than that of the water body. Therefore, we set a single-band threshold to control the interference caused by artificial ground and shadows based on water's overall low reflectance. More importantly, it can remove the extra non-water that is caused by the looser NDWI threshold. The discriminant for water body extraction is as follows:

$$
N D W I>-0.3 \cap N I R<0.08,
$$


In the remote sensing image, when the pixels have noise, it will cause the inaccurate extraction result of the water body. For example, abnormal pixels appear in the homogeneous water, resulting in the omission of water, or, at the edge of the boundary between the water and other features, the water pixels may be fragmented due to the change in reflectance. To correct this situation, a fragmentary pixel correction was added after the water body extraction. After comparing 8 points in the $3 \times 3$ neighborhood, the value of the center pixel of the window was obtained, and this value was used to reflect the water body information of the area. When the pixel is filled, the attributes of the center pixel and the surrounding pixels remain the same [44]. It can be seen from Figure 4 that the correction can eliminate the omission and misjudgment in details and can improve the accuracy of water body extraction.
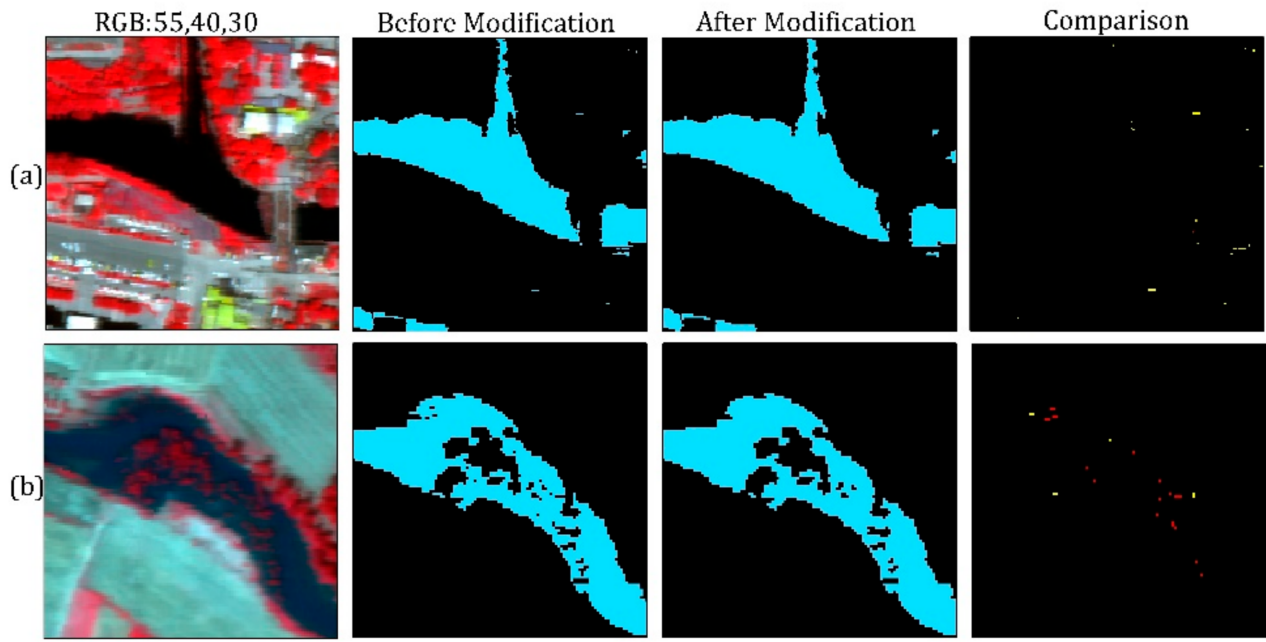

Figure 4. Fragmentary pixel correction and water body extraction results: in the comparison column, yellow represents removed pixels and red represents filled pixels. Some fragmented pixels in (a) that were incorrectly extracted have been removed, while the water pixels in (b) around vegetation in the water are filled.

\subsection{Water Quality Parameter Retrieval}

At present, the monitoring of black and odorous water bodies focuses on mainly small-scale waters whose water quality parameter selection is based on experience or correlation. In this paper, the water quality parameters regarded as the reference were directly used as the input parameter of CBOWI. It not only takes into account the black and odor mechanism, as with the colorimetric method and the band method, but also has better wide-ranging adaptability than other algorithms [45].

\subsubsection{Band Combination Selection}

In addition to the single band, the water reflectance characteristics can also be expressed in terms of a ratio [46]. The reflectance spectrum curve after the envelope removal process has a larger fluctuation range, which is better for analyzing the sensitive bands of various retrieved parameters. Firstly, the numerical values of the four parameters were sorted. Then, we selected around 10 groups of the largest and smallest water quality values of each parameter to compare the overall difference in spectral characteristics (Figure 5). It was expected that there would be individual curve characteristics different from the general trend in the figure. This was because there are many factors that affect the reflectance characteristics of the water body with complexity. In the analysis, we focused on the overall trend of the curves, and compared the difference between high and low values of one parameter.

It can be seen from the figure that different parameters have both similar characteristic bands and different characteristic bands within the entire spectrum interval. This can 
not only show the sensitive and non-sensitive bands of a certain parameter at different concentrations, but also include the influence of other water quality parameters to ensure the facticity. For $\mathrm{NH}_{3}-\mathrm{N}$, there are peaks and valleys in band 49 and band 43 respectively, showing a trend of decreasing with the high $\mathrm{NH}_{3}-\mathrm{N}$ value. In addition, band 53 and band 63 also have peaks and valleys. Although the sensitive and insensitive band slopes of the low and high value are not quite distinct in the two pairs, they are more useful than other characteristics. For ODO, when ODO is low, the envelope removal result of band 20 is close to 1 . When ODO is high, its result is low; band 25 is not sensitive to ODO concentrations, so band 20 and band 25 are selected as a band combination. In the same way, band 44 and band 49 , band 49 and band 54 are also selected as band combinations. As for ORP, around band 20, it can be seen that the low ORP value tends towards 1, while it fluctuates downward when it is a high value. Moreover, the insensitive band is between band 25 and band 32. Therefore, the bands corresponding to the maximum and minimum values between band 18 and band 32 are taken as a set of band combinations. The band number of this combination is not fixed. It can be seen that in bands 50-63, the high-value ORP has large fluctuation, while the low value does not have fluctuation; therefore, the bands corresponding to the maximum and minimum values of band 50 to band 63 are combined as a set of bands. For TUR, between band 45 and band 53, the low-value TUR presents a feature of greater fluctuation than the high value, so the band corresponding to the maximum and minimum values in this interval is selected. In band 54, the low-value TUR is generally lower than the high TUR, so band 48 and band 54 are also selected as a combination. Information of band combination is shown in Table 5. To combine the characteristic pairs, the normalization method is used in this paper.
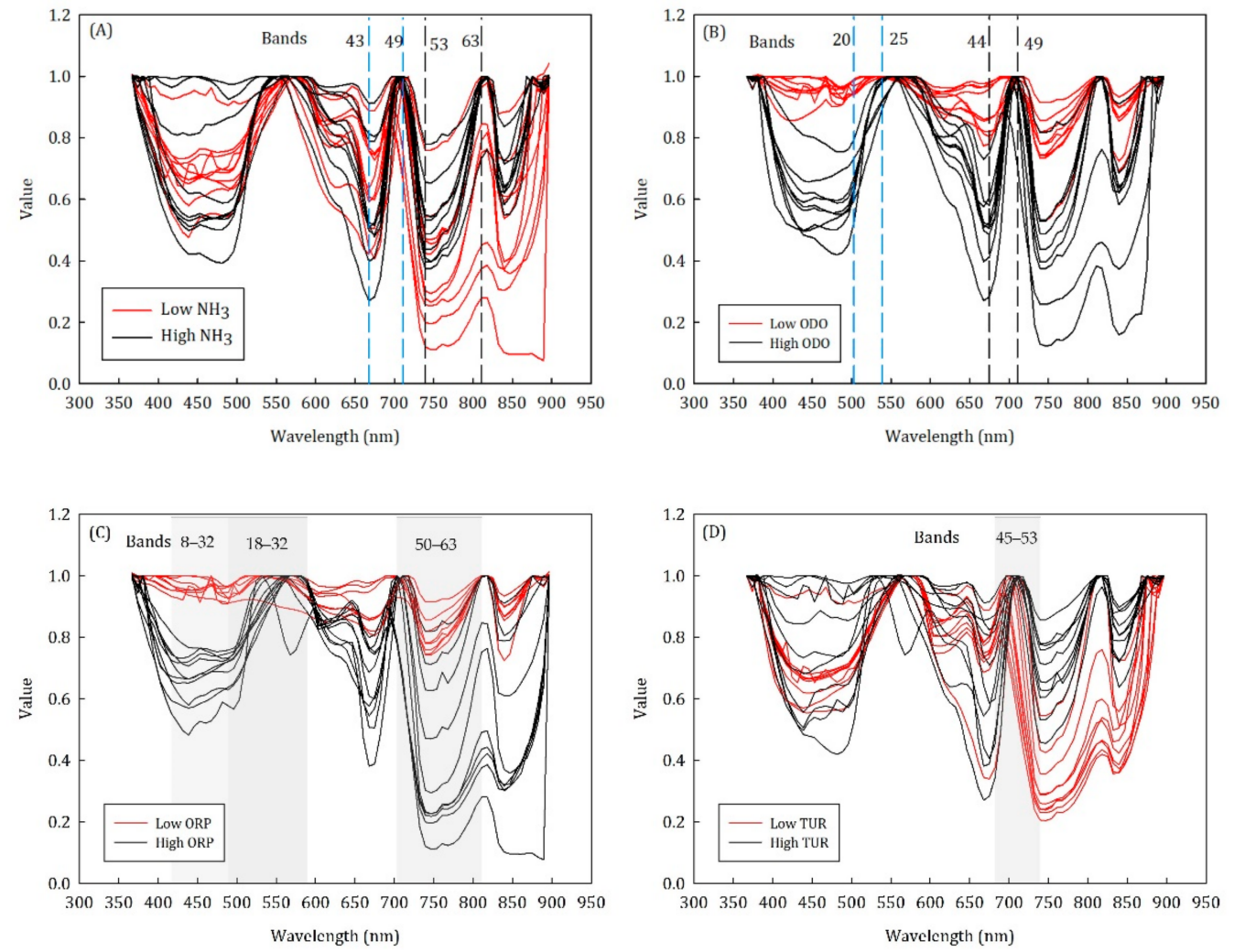

Figure 5. Differences in spectrum curves of the maximum and minimum: (A) $\mathrm{NH}_{3}-\mathrm{N},($ B) $\mathrm{ODO}$, (C) ORP and (D) TUR. 
Table 5. Band combination information of the four water quality parameters.

\begin{tabular}{ccccc}
\hline & $\mathbf{N H}_{3}-\mathbf{N}$ & ODO & ORP & TUR \\
\hline \multirow{3}{*}{ Band combination } & 43,49 & 20,25 & $\begin{array}{c}\operatorname{Max}(18-32), \\
\operatorname{Min}(8-32)\end{array}$ & $\begin{array}{l}\text { Max (45-53), } \\
\text { Min (45-53) } \\
\end{array}$ \\
& 53,63 & 44,49 & $\operatorname{Min}(50-63)$, & \\
\hline
\end{tabular}

\subsubsection{Water Quality Parameter Retrieval Based on Random Forest}

Random forest [47] is a supervised learning algorithm that is integrated based on decision tree learners. It is easy to implement and efficient to compute and has shown impressive performance for classification and regression tasks. This method has good accuracy, can process high-dimensional data samples and has the characteristics of strong anti-interference and anti-overfitting capabilities.

Although the water quality parameters obtained by field observation do not have optical characteristics, the differences in water quality parameters are directly related to the pollution situation [48], and the differences in water quality also have different manifestations in the spectrum. Therefore, we established a relationship between the two through the random forest method. In this study, except for images covered by other ground features (such as aquatic plants, clouds, etc.) and poor data quality, a total of 46 remote sensing image sampling points corresponding to the measured water quality data were obtained. A body of water has a uniform texture within a certain range [49], and the water quality can be seen as the same when there is no mutation. Based on this, we adopted a sample expansion [50], which was used to expand approximately 100-150 pixels around the measured point. Therefore, the total number of sample points participating in random forest training was 6615 . In random forest training, the input variables were the reflectance of all bands and the combinations of characteristic bands mentioned in Section 3.2.1. The training results were the water quality parameter values.

\subsection{Continuous Black and Odorous Water Monitoring Model}

According to the grading standard in Table 2, the CBOWI was proposed and modeled by the partial least squares (PLS) [51] method. PLS is a mathematical optimization technique that finds the best function match for a set of data by minimizing the sum of squares of errors. It uses the simplest method to find unknown true values and minimize the sum of squared errors. This method can be used when the amount of data is small and there may be a correlation between independent variables. Relatively speaking, if a fixed label is divided, the discrimination degree with a nonlinear random forest will become lower. In this study, we aimed to obtain a continuous evaluation index for black and odorous water. Using PLS compared to random forest can better characterize the linear relationship. When using machine learning training, the input $Y$ is the black and odorous water grades, and the input $\mathrm{Xs}$ are the four water quality parameter values obtained from the retrieval, the black and odor grade corresponding to each water quality parameter and the normalized value of each water quality parameter in the corresponding grade interval. The normalized value can quantify the pollution degree of each evaluation parameter within their grade. The final $\mathrm{CBOWI}$ result is a continuous value, which represents the degree of black odor pollution.

\section{Result}

\subsection{Model Accuracy Evaluation of Water Quality Parameters and CBOWI}

The model accuracy of water quality retrieval and CBOWI is described in this section. The evaluation criteria of the model building are the coefficient of determination ( $\mathrm{R}^{2} \_$Score), root mean squared error (RMSE), mean absolute error (MAE) and Pearson correlation coefficient (Pearson- $\mathrm{R}^{2}$ ). Among them, the $\mathrm{R}^{2}{ }_{-}$Score can evaluate the goodness of fit of regression model coefficients, and RMSE and MAE can measure the deviation and error between the predicted value and the true value. 
For the random forest model of water quality parameters and PLS model for the CBOWI index, based on the idea of cross-validation, 50 tests were performed on different randomly grouped training sets and test sets (the ratio of training samples to test samples was 4:1) to test the generalization ability of the model after fitting.

As for water quality parameter retrieval models, out-of-bag samples were used to evaluate the quality of the model. After 50 modeling tests, the ones with the smallest error were selected as the final models. According to Table 6, the out-of-bag fitting accuracy (OOB_Score) of the four water quality models was high, with values above 0.95. Simultaneously, the models also had small RMSE and MAE. In addition, for the 50 times modeling, the average $\mathrm{R}^{2} \_$Score and RMSE of the test data statistics were also high, showing good robustness. In summary, the four water quality parameter models had good fitting accuracy and generalization ability.

Table 6. Accuracy evaluation of water quality parameters models.

\begin{tabular}{cccccc}
\hline & \multicolumn{3}{c}{ Adopted Model } & \multicolumn{2}{c}{ Average of 50 Modeling Tests } \\
\cline { 2 - 6 } & OOB_Score & RMSE (Min, Max) & MAE & R $^{2}$ _Score (Test) & RMSE \\
\hline $\mathrm{NH}_{3}-\mathrm{N}$ & 0.965 & $0.473(0.03,42.08)$ & 0.158 & 0.963 & 0.965 \\
$\mathrm{ODO}$ & 0.959 & $0.628(0.08,20.31)$ & 0.8343 & 0.972 & 1.123 \\
$\mathrm{ORP}$ & 0.972 & $10.120(-320,219.1)$ & 9.5158 & 0.984 & 1.637 \\
TUR & 0.985 & $1.124(0.33,56.51)$ & 2.1227 & & \\
\hline
\end{tabular}

As for the CBOWI model, a validation similar to the above was applied and, finally, the model with the highest Pearson- $\mathrm{R}^{2}$ was adopted as the one to use. However, CBOWI does not have a direct verification method. To indirectly verify the recognition accuracy of CBOWI and further prove the effectiveness of it, in addition to the criteria mentioned above, the accuracy rate (CR) of black and odorous water body classification was also used. In it, NCP is the number of pixels that are correctly classified as a black and odorous water body, and NTP is the number of total verification pixels.

$$
\mathrm{CR}=\frac{\mathrm{NCP}}{\mathrm{NTP}}
$$

In order to use the CR mentioned above and verify the accuracy of this index, this study adopted an indirect verification method, i.e., CBOWI was converted into black and odor grades according to a certain threshold, and then was compared with the standard black and odor grade by CR. The thresholds were set as: clean (CBOWI < 1.5$)$, mild $(1.5 \leq \mathrm{CBOWI}<2.5)$ and severe $(\mathrm{CBOWI} \geq 2.5)$.

The model accuracy evaluation is shown in Table 7. According to it, the Pearson- $\mathrm{R}^{2}$ of the adopted model was 0.971 , which indicates high fitting accuracy. The $\mathrm{R}^{2}$ _Score, RMSE and MAE of the verification data were $0.738,0.469$ and 0.39 , respectively. CR shows that the classification accuracy after converting CBOWI to black and odor grades is 0.722 . We still calculated the average accuracy of the 50 times modeling, and it could be seen that the accuracy was close to the selected model, which reflects the good generalization ability and robustness of the model.

Table 7. CBOWI model accuracy evaluation.

\begin{tabular}{cccccc}
\hline & Pearson- $\mathbf{R}^{\mathbf{2}}$ & $\mathbf{R}^{\mathbf{2}}$ _Score (Test) & RMSE & MAE & CR \\
\hline Adopted model & 0.971 & 0.738 & 0.469 & 0.39 & 0.722 \\
Average of 50 modeling tests & 0.894 & 0.706 & 0.421 & - & 0.823 \\
\hline
\end{tabular}




\subsection{Black and Odorous Water Result of Rivers in Baoding}

In this section, the CBOWI results of major rivers in the urban area of Baoding are displayed. This article analyzes the sources of pollution in some of the polluted areas. Furthermore, detailed results in local areas are analyzed.

Figure 6 shows the CBOWI of some rivers in the Baoding urban area. As can be seen from the figure, there is no very high CBOWI area. In this figure, the clean water body represents the majority, followed by the mild black and odorous water body, and some areas have severe black and odorous water bodies. The parts in the red frames are the more black and odorous water bodies, and the causes of the black and odor in these areas were analyzed.

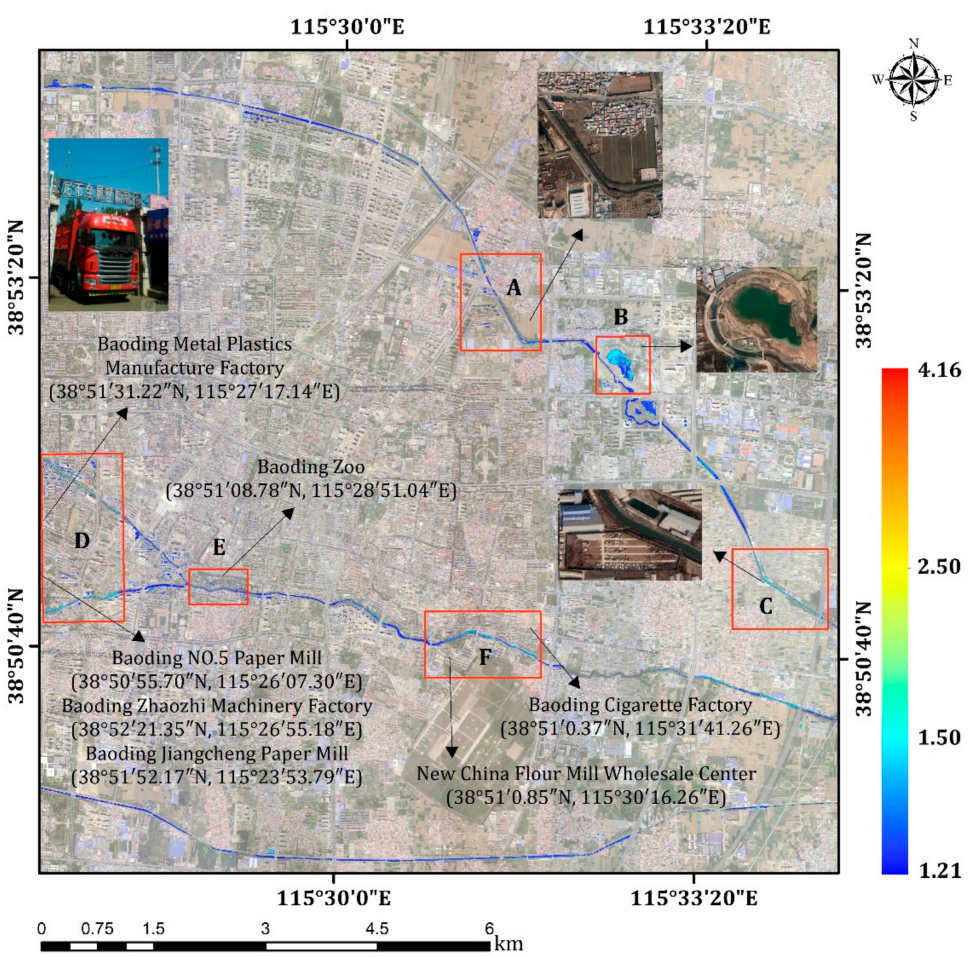

Figure 6. CBOWI map of example rivers in Baoding urban area.

" $\mathrm{A}$ " is the water flowing through residential areas and cultivated land with apparently mild pollution, which is mostly caused by domestic sewage and agricultural sewage. It is necessary to pay attention to the situation of sewage and drainage in this area. As for " $\mathrm{B}$ ", the black and odor is mainly caused by the turbidity, which is related to the low fluidity of the water body and the surrounding environment. " $\mathrm{C}$ " is a moderately mild black and odor area. The pollution here is mainly due to excrement, feed and flushing water of a breeding farm in this area. " $\mathrm{D}$ " has a mild black odor and severe black odor, which is with a higher degree of black odor. The main reason is that there are metal factories, plastic factories, paper mills and breeding farms near the area, making it likely that the water body is polluted. In " $\mathrm{E}$ ", there is a zoo, leading to pollution mainly composed of breeding sewage and tourist activities. " $\mathrm{F}$ " is also a mild black and odor area. There is a cigarette factory and a flour factory here, which will produce waste water.

For a more detailed analysis with the water quality parameters in Figure 7, there are three different representative local areas: urban rivers, urban lakes and suburban water bodies. From Figure 7A, the mild black and odor of the lake (the red box) is mainly reflected in the high TUR, which may be the result of the low fluidity of the water body and the accumulation of suspended solids in the water. When in a residential area (the yellow box), there is no higher turbidity, but higher $\mathrm{NH}_{3}-\mathrm{N}$ appears. This phenomenon is mainly related to the discharge of domestic water. The main body of water in Figure $7 \mathrm{~B}$ is a river 
that passes through the city. The middle section of the river (the yellow box) and the right end (the red box) have a higher CBOWI, and the pollution on the side of the river near the residential area is greater. The area with high black and odor in this section of the river is also mainly caused by high $\mathrm{NH}_{3}-\mathrm{N}$, and there is also a part of the water body that is turbid. Figure $7 \mathrm{C}$ is the area where the river flow is dominated by cultivated land (not in Figure 6). The overall black and odor of the river is relatively lower than that in urban areas. According to the CBOWI, there is a small area that is mildly black and odorous in the paddy field area. Compared with urban areas, the overall turbidity of the water bodies in the suburbs is lower. The relatively high $\mathrm{NH}_{3}-\mathrm{N}$ in the four tributaries of the river may be related to the discharge of fertilizers from agriculture. The distribution of pollution levels can also be seen in the figure: there are changes in pollution concentration near the edge of the land and tributaries, and even some point source-like pollution areas can be found (the red circles).

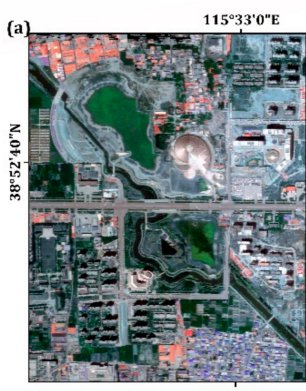

(d)

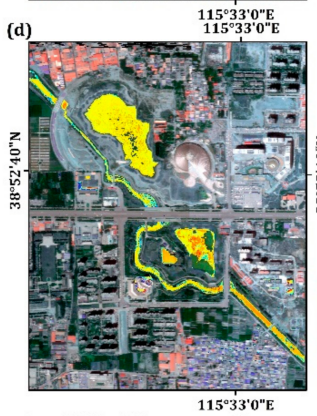

$\underline{0.275} \quad 0.5$

(A) A lake in Baoding urban area
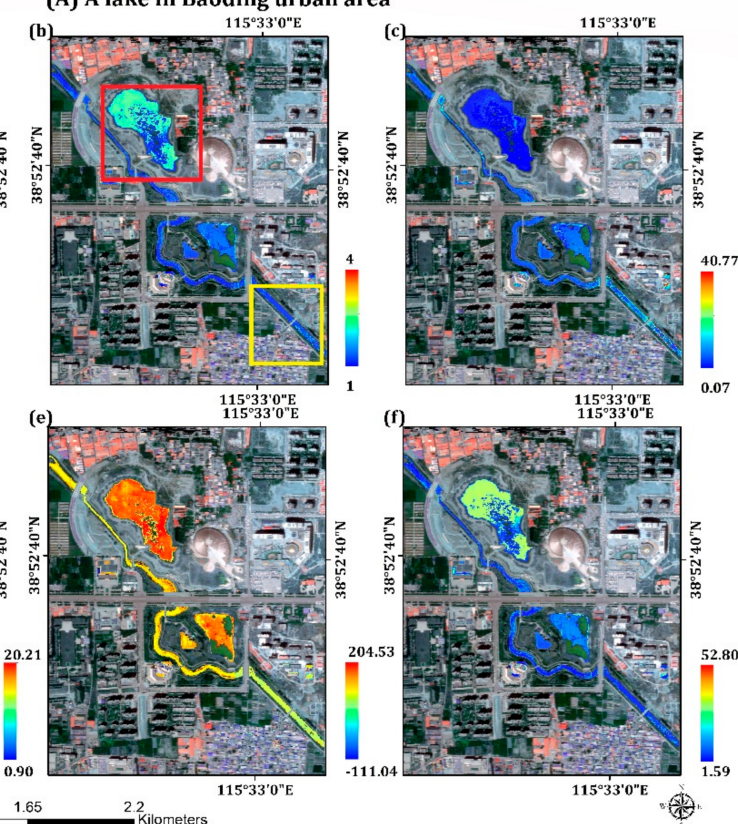

(B) A river in Baoding urban area

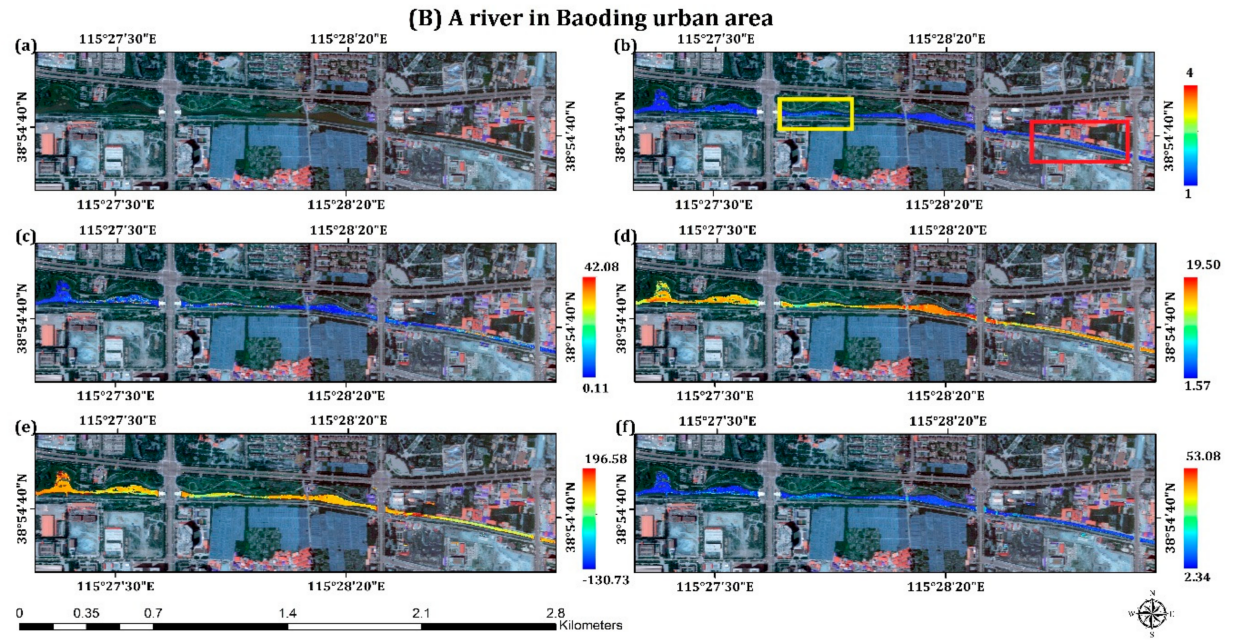

Figure 7. Cont. 
(C) Water bodies in Baoding suburban area
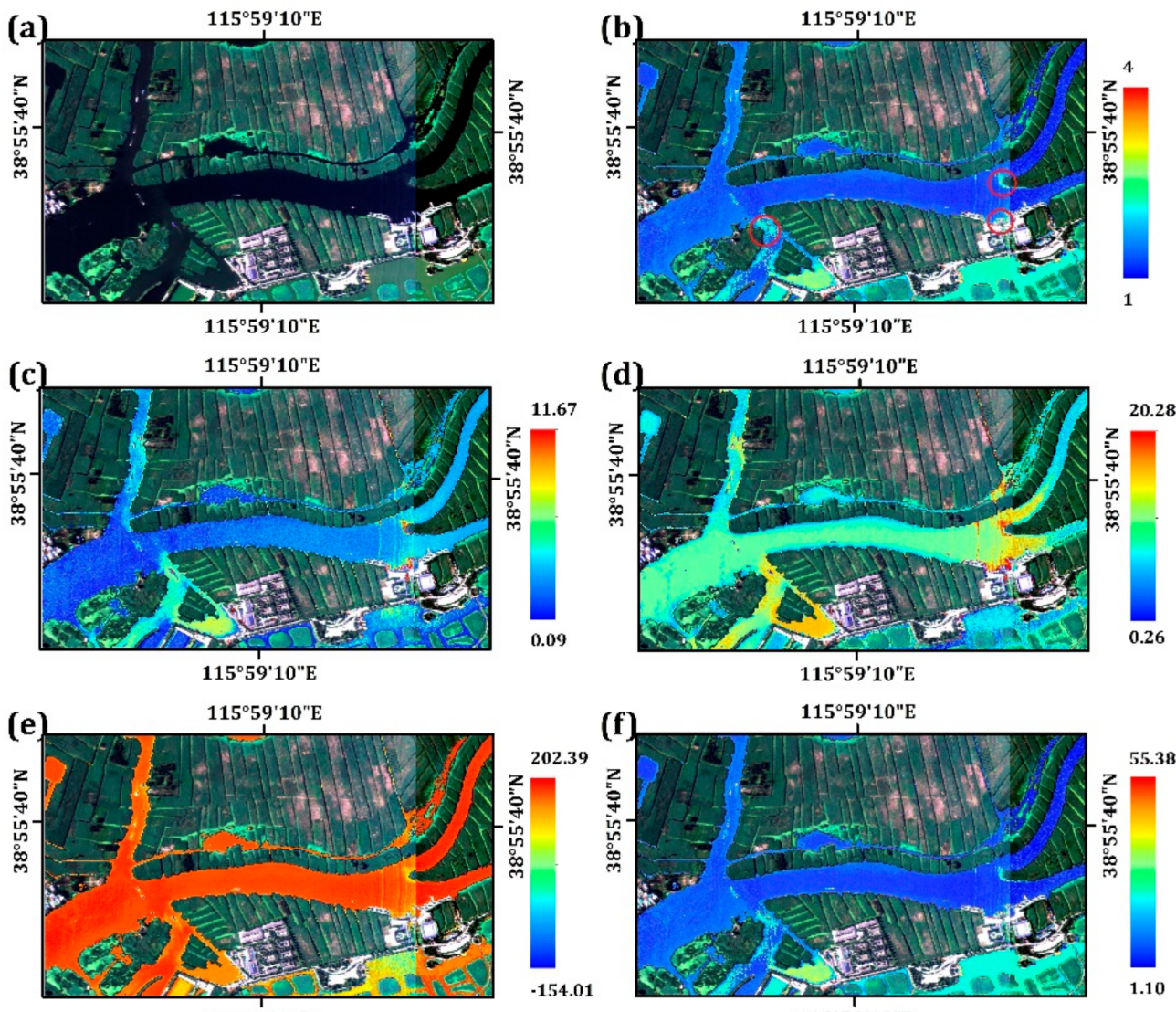

$115^{\circ} 59^{\prime} 10^{\prime \prime} \mathrm{E}$
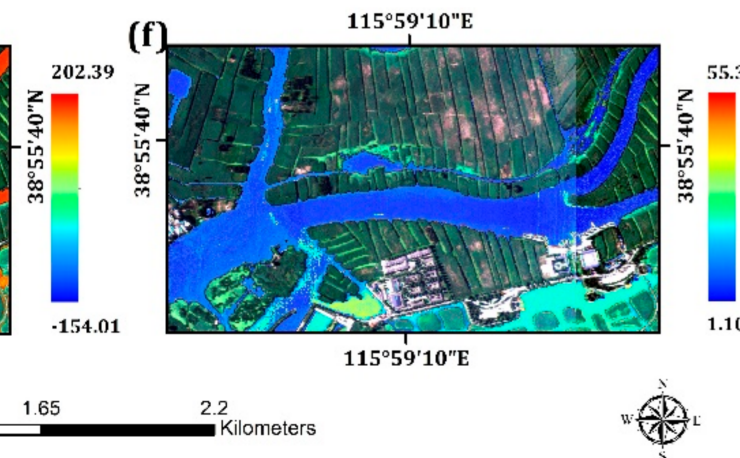

Figure 7. Local CBOWI and water quality parameter retrieval results: (a) true color image, (b) CBOWI, (c) NH3-N, (d) ODO, (e) ORP and (f) TUR.

In general, convincing results have been achieved in the treatment of black and odorous water in the Baoding area. There are a few areas with severe pollution, and some mildly black and odorous water bodies, which are similar to clean water. The main factors leading to these black and odorous water bodies are the discharge of domestic sewage and factory sewage, as well as the influence of fertilizers on the water body in cultivated land areas. It can be seen that the implementation of this CBOWI in the Baoding area can provide assistance and a reference for the government's decision-making on the treatment of black and odorous water bodies.

\section{Conclusions}

With the acceleration of urbanization, the black and odorous water body has become a widespread water environmental pollution issue. Studies on black and odorous water are mostly based on the formation mechanism and evaluation system; studies on the classification of black and odorous water bodies are not mature enough. The method of laboratory analysis of water quality samples has limitations in time and space. Remote sensing technology can overcome this limitation, but different water areas require different modeling parameters according to the situation. In addition, current research is mostly focused on qualitative classification. However, continuous spatial information is of great importance to find the source of black and odorous water and evaluate the degree of black and odorous water. 
In order to overcome the above problems, in this paper, the continuous black and odor water index, CBOWI, modeled by partial least squares (PLS) using four water quality parameters-optical dissolved oxygen (ODO), oxidation-reduction potential (ORP), $\mathrm{NH}_{3}-\mathrm{N}$ and turbidity (TUR) - obtained by random forest is proposed according to the black and odor grading standard of the national guide. As for validation, the Pearson- $\mathrm{R}^{2}$ of the CBOWI model fitness is 0.971 and the correct rate is 0.738 . Moreover, the CBOWI results are shown globally and locally in the Baoding area. According to the analysis, the overall degree of black and odorous water in the Baoding urban area is not significantly high, and most of the water is clean water, with some mild and less severe cases of black and odorous water. The sources of black and odorous water are mainly domestic and factory sewage. Black and odorous water can also occur in farmland areas, mostly caused by fertilizers.

In general, the proposed method combined with a black and odor grading standard can be easily generalized, and would also be useful for continuous quantitative pollution monitoring programs. This, in turn, may support a new approach to monitoring black and odorous water bodies. It can also have a key role in identifying the source(s) of pollution and evaluating mitigating treatments. Finally, this system could provide supporting evidence for water quality managers and policy-makers.

Author Contributions: Conceptualization, X.Z. and Z.H.; methodology, X.Z. and Z.H.; software, B.N. and Y.Z.; validation, X.Z.; investigation, X.Z.; resources, B.N., Y.Z. and M.W.; data curation, B.N. and Y.Z.; writing-original draft preparation, X.Z. and S.L.; writing-review and editing, X.Z. and T.W.; visualization, X.Z.; supervision, Y.W. and Z.H. All authors have read and agreed to the published version of the manuscript.

Funding: This research was funded by the National Key Research and Development Program of China, grant number 2018YFD1100405; the National Key Research and Development Program of China, grant number 2016YFC0600210; the National Natural Science Foundation of China, grant number 41272366 and the Science and Technology Innovation Program of China Metallurgical Geology Bureau, grant number CMGB202001.

Institutional Review Board Statement: Not applicable.

Informed Consent Statement: Not applicable.

Data Availability Statement: The data presented in this study are available on request from the corresponding author.

Conflicts of Interest: The authors declare no conflict of interest.

\section{References}

1. Cao, J.; Sun, Q.; Zhao, D.; Xu, M.; Shen, Q.; Wang, D.; Wang, Y.; Ding, S. A critical review of the appearance of black-odorous waterbodies in China and treatment methods. J. Hazard. Mater. 2020, 385, 121511. [CrossRef]

2. Gao, J.; Jia, J.; Xing, F.; Wang, Y.; Xu, X.; Yang, Y.; Zou, X.; Gao, S.; Qi, S. Changes in water and sediment exchange between the Changjiang River and Poyang Lake under natural and anthropogenic conditions, China. Sci. Total Environ. 2014, 481, 542-553. [CrossRef]

3. Perera, E.D.P.; Jinno, K.; Hiroshiro, Y. Bacteria-mediated Reduction and Precipitation of $\mathrm{Fe}(\mathrm{OH})_{3}$ and FeS in the Subsurface of a Coastal Aquifer: A Numerical Investigation. Water Qual. Exp. Health 2010, 2, 15-30. [CrossRef]

4. Negoro, T.; Ando, M.; Ichikawa, N. Blue-green algae in Lake Biwa which produce earthy-musty odors. Water Sci. Technol. 1988, 20, 117-123. [CrossRef]

5. Ji, G. Research and Application on Black and Odorous Water Body by Remote Sensing. Master's Thesis, Lanzhou Jiaotong University, Lanzhou, China, 2016.

6. Hu, Y.; Cheng, H. Water pollution during China's industrial transition. Environ. Dev. 2013, 8, 57-73. [CrossRef]

7. Song, C.; Liu, X.; Song, Y.; Liu, R.; Gao, H.; Han, L.; Peng, J. Key blackening and stinking pollutants in Dongsha River of Beijing: Spatial distribution and source identification. J. Environ. Manag. 2017, 200, 335-346. [CrossRef]

8. More Than 70\% of Cities across the Country Have Found Black and Odorous Water Bodies. Available online: http:/ /www.gov. cn/xinwen/2016-02/21/content_5044214.htm (accessed on 23 December 2021).

9. Notice of the Ministry of Housing and Urban Rural Development and the Ministry of Ecological Environment on Printing and Distributing the Implementation Plan for the Key Battle of Urban Black and Odorous Water Treatment. Available online: http://www.mohurd.gov.cn/gongkai/fdzdgknr/tzgg/201810/20181015_237912.html (accessed on 23 December 2021). 
10. Wang, X.; Wang, Y.; Sun, C.; Pan, T. Formation mechanism and assessment method for urban black and odorous water body: A review. J. Appl. Ecol. 2016, 27, 1331-1340.

11. Gholizadeh, M.H.; Melesse, A.M.; Reddi, L. A comprehensive review on water quality parameters estimation using remote sensing techniques. Sensors 2016, 16, 1298. [CrossRef]

12. Ritchie, J.C.; Zimba, P.V.; Everitt, J.H. Remote Sensing Techniques to Assess Water Quality/Técnicas de teledetección para evaluar la calidad del agua. Photogramm. Eng. Remote Sens. 2003, 69, 695-704. [CrossRef]

13. Myneni, R.B.; Maggion, S.; Iaquinta, J.; Privette, J.L.; Gobron, N.; Pinty, B.; Kimes, D.S.; Verstraete, M.M.; Williams, D.L. Optical remote sensing of vegetation: Modeling, caveats, and algorithms. Remote Sens. Environ. 1995, 51, 169-188. [CrossRef]

14. Wang, H.; He, N.; Zhao, R.; Ma, X. Soil water content monitoring using joint application of PDI and TVDI drought indices. Remote Sens. Lett. 2020, 11, 455-464. [CrossRef]

15. Zhang, J.; Zhang, Q.; Bao, A.; Wang, Y. A new remote sensing dryness index based on the near-infrared and Red spectral space. Remote Sens. 2019, 11, 456. [CrossRef]

16. Chen, G.; Li, S.; Knibbs, L.D.; Hamm, N.A.S.; Cao, W.; Li, T.; Guo, J.; Ren, H.; Abramson, M.J.; Guo, Y. A machine learning method to estimate PM2.5 concentrations across China with remote sensing, meteorological and land use information. Sci. Total Environ. 2018, 636, 52-60. [CrossRef]

17. $\mathrm{Wu}, \mathrm{S}$. Research progress of remote sensing monitoring key technologies for urban black and odorous water bodies. Chin. J. Environ. Eng. 2019, 13, 1261-1271. [CrossRef]

18. Chen, G.; Luo, J.; Zhang, C.; Jiang, L.; Tian, L.; Chen, G. Characteristics and influencing factors of spatial differentiation of urban black and odorous waters in China. Sustainability 2018, 10, 4747. [CrossRef]

19. Zhang, S.; Chen, X.; Ye, Q.; Zhang, Z.; Wang, J. Dissolved Metal(loid) Concentrations and Their Relations with Chromophoric and Fluorescent Dissolved Organic Matter in an Urban River in Shenzhen, South China. Water 2020, 12, 281. [CrossRef]

20. Ding, X.L.; Li, Y.M.; Lü, H.; Zhu, L.; Wen, S.; Lei, S.H. Analysis of Absorption Characteristics of Urban Black-odor Water. Huanjing Kexue/Environ. Sci. 2018, 39, 4519-4529. [CrossRef]

21. Cao, Y.S.; Tang, J.G.; Henze, M.; Yang, X.P.; Gan, Y.P.; Li, J.; Kroiss, H.; Van Loosdrecht, M.C.M.; Zhang, Y.; Daigger, G.T. The leakage of sewer systems and the impact on the "black and odorous water bodies" and WWTPs in China. Water Sci. Technol. 2019, 79, 334-341. [CrossRef] [PubMed]

22. Zhang, D.; Yang, H.; Lan, S.; Wang, C.; Li, X.; Xing, Y.; Yue, H.; Li, Q.; Wang, L.; Xie, Y. Evolution of urban black and odorous water: The characteristics of microbial community and driving-factors. J. Environ. Sci. 2022, 112, 94-105. [CrossRef]

23. Shen, Q.; Zhu, L.; Cao, H. Remote sensing monitoring and screening for urban black and odorous water body: A review. Chin. J. Appl. Ecol. 2017, 28, 3433-3439.

24. Duan, H.; Ma, R.; Loiselle, S.A.; Shen, Q.; Yin, H.; Zhang, Y. Optical characterization of black water blooms in eutrophic waters. Sci. Total Environ. 2014, 482-483, 174-183. [CrossRef]

25. Wen, S.; Wang, Q.; Li, Y.; Zhu, L.; Lv, H.; Lei, S.; Ding, X.; Miao, S. Remote Sensing Identification of Urban Black- Odor Water Bodies Based on High- Resolution Images: A Case Study in Nanjing. Huanjing Kexue/Environ. Sci. 2018, 39, 57-67.

26. Cao, H. Study on Analysis of Optical Properties and Remote Sensing Identifiable Models of Black and Malodorous Water in Typical Cities in China. Master's Thesis, Southwest Jiaotong University, Chengdu, China, 2017.

27. Huang, Z.; Zheng, J. Extraction of Black and Odorous Water Based on Aerial Hyperspectral CASI Image. In Proceedings of the IGARSS 2019-2019 IEEE International Geoscience and Remote Sensing Symposium, Yokohama, Japan, 28 July-2 August 2019; pp. 6907-6910. [CrossRef]

28. Canfield, D.E.; Linda, S.B.; Hodgson, L.M. Relations Between Color and Some Limnological Characteristics of Florida Lakes. J. Am. Water Resour. Assoc. 1984, 20, 323-329. [CrossRef]

29. Wei, C.; Zheng, Q.; Shang, Y.; Zhang, X.; Yin, J.; Shen, Z. Black and Odorous Water Monitoring by Using GF Series Remote Sensing Data. In Proceedings of the 2021 9th International Conference on Agro-Geoinformatics (Agro-Geoinformatics), Shenzhen, China, 26-29 July 2021; pp. 1-6. [CrossRef]

30. Sarigai; Yang, J.; Zhou, A.; Han, L.; Li, Y.; Xie, Y. Monitoring urban black-odorous water by using hyperspectral data and machine learning. Environ. Pollut. 2021, 269, 116166. [CrossRef] [PubMed]

31. Mobley, C.D. Estimation of the remote-sensing reflectance from above-surface measurements. Appl. Opt. 1999, $38,7442$. [CrossRef] [PubMed]

32. Li, Y.; Li, Y.; Wu, W. Threshold and resilience management of coupled urbanization and water environmental system in the rapidly changing coastal region. Environ. Pollut. 2016, 208, 87-95. [CrossRef] [PubMed]

33. Wang, L.; Liu, C.; Wang, S.; Han, Z.; Du, Y. The Variation Law of Water Environment Quality in the Haihe River Basin in 2005-2016 and Analysison the Law. In Proceedings of the 2018 3rd International Conference on Smart City and Systems Engineering (ICSCSE), Xiamen, China, 29-30 December 2018; pp. 923-929. [CrossRef]

34. Li, C.; Zheng, X.; Zhao, F.; Wang, X.; Cai, Y.; Zhang, N. Effects of urban non-point source pollution from Baoding City on Baiyangdian Lake, China. Water 2017, 9, 249. [CrossRef]

35. Ministry of Housing and Urban-Rural Development of the People's Republic of China. Notice on Printing and Distributing the Guidelines for the Remediation of Urban Black and Odorous Waters. Available online: http:/ /www.mohurd.gov.cn/wjfb/2015 09/t20150911_224828.html (accessed on 10 September 2018). 
36. Paaijmans, K.P.; Takken, W.; Githeko, A.K.; Jacobs, A.F.G. The effect of water turbidity on the near-surface water temperature of larval habitats of the malaria mosquito Anopheles gambiae. Int. J. Biometeorol. 2008, 52, 747-753. [CrossRef] [PubMed]

37. Zhang, X.; Li, C.; Jia, K.; Wu, T.; Li, W. Spatial-temporal changes in water transparency and its impact factors in Lake Wuliangsuhai. J. Lake Sci. 2009, 21, 879-884. [CrossRef]

38. Tang, J.; Tian, G.; Wang, X.; Wang, X.; Song, Q. The Methods of Water Spectra Measurement and AnalysisI: Above-Water Method. J. Remote Sens. 2004, 8, 37-44.

39. Press, W.H.; Teukolsky, S.A. Savitzky-Golay Smoothing Filters. Comput. Phys. 1990, 4, 669. [CrossRef]

40. Xu, P. Research and application of near-infrared spectroscopy in rapid detection of water pollution. Desalin. Water Treat. 2018, 122, 1-4. [CrossRef]

41. Ma, S.; Zhou, Y.; Gowda, P.H.; Dong, J.; Zhang, G.; Vijaya, G.; Wagle, P.; Chen, L.; Flynn, K.C.; Jiang, W. Application of the water-related spectral reflectance indices: A review. Ecol. Indic. 2019, 98, 68-79. [CrossRef]

42. McFeeters, S.K. The use of the Normalized Difference Water Index (NDWI) in the delineation of open water features. Int. J. Remote Sens. 1996, 17, 1425-1432. [CrossRef]

43. Liu, Y. Why NDWI threshold varies in delineating water body from multitemporal images? Int. Geosci. Remote Sens. Symp. 2012, 4375-4378. [CrossRef]

44. Sun, L.; Zhou, X.; Wei, J.; Wang, Q.; Liu, X.; Shu, M.; Chen, T.; Chi, Y.; Zhang, W. A New Cloud Detection Method Supported by GlobeLand30 Data Set. IEEE J. Sel. Top. Appl. Earth Obs. Remote Sens. 2018, 11, 3624-3645. [CrossRef]

45. Rügner, H.; Schwientek, M.; Beckingham, B.; Kuch, B.; Grathwohl, P. Turbidity as a proxy for total suspended solids (TSS) and particle facilitated pollutant transport in catchments. Environ. Earth Sci. 2013, 69, 373-380. [CrossRef]

46. Kuang, D.; Han, X.; Liu, X.; Zhan, Y.; Niu, Z.; Wang, L. Quantitative estimation of Taihu chlorophyll-a concentration using HJ-1A and 1B CCD imagery. China Environ. Sci. 2010, 30, 1268-1273.

47. Breiman, L. Random forests. Mach Learn. 2001, 45, 5-32. [CrossRef]

48. Shen, Q.; Yao, Y.; Li, J.; Zhang, F.; Wang, S.; Wu, Y.; Ye, H.; Zhang, B. A CIE color purity algorithm to detect black and odorous water in urban rivers using high-resolution multispectral remote sensing images. IEEE Trans. Geosci. Remote Sens. 2019, 57, 6577-6590. [CrossRef]

49. Luo, J.; Sheng, Y.; Shen, Z.; Li, J. High-precise water extraction based on spectral-spatial coupled remote sensing information. Int. Geosci. Remote Sens. Symp. 2010, 2840-2843. [CrossRef]

50. Yue, Y.; Gong, J.; Wang, D. The Extraction of Water Information Based on SPOT5 Image Using Object-Oriented Method. In Proceedings of the 2010 18th International Conference on Geoinformatics, Beijing, China, 18-20 June 2010. [CrossRef]

51. Geladi, P.; Kowalski, B.R. Partial Least-Squares Regression: A Tutorial. Anal. Chim. Acta 1986, 185, 1-17. [CrossRef] 